\title{
ASSESMENT OF CLINICAL EFFECTIVENESS OF LOSARTAN AND AMLODIPINE IN HYPERTENSIVE PATIENTS WITH LEFT VENTRICULAR HYPERTROPHY
}

\author{
PILLAI RUTUPARNA, DANA MERIN, SUJA ABRAHAM, NOBLE MOTTY THOMAS, JAHANARA HAMEED*
}

Department of Pharmacology, Amrita School of Pharmacy, Amrita Institute of Medical Sciences and Research Centre, Amrita Vishwa Vidyapeetham, Amrita University, Kochi - 682 041, Kerala, India. Email: jhameed@aims.amrita.edu

Received: 04 January 2017, Revised and Accepted: 01 March 2017

\section{ABSTRACT}

Objective: Hypertension is an important worldwide public health challenge because of its high frequency and concomitant risks of cardiovascular and kidney diseases. Left ventricular hypertrophy (LVH) is defined as an increase in the mass of the LV, which can be secondary to an increase in wall thickness, an increase in cavity size, or both. Relevant study reported that LVH is one of the major and independent risk factors for coronary artery disease, heart failure, serious dysrhythmias, and sudden death. Thus, regression of LVH is a primary pharmacologic objective. The objective of this study is to assess the effectiveness of losartan and amlodipine in regression of LVH and to monitor the adverse effects of these drugs on monotherapy. The study also focused to estimate the clinical effectiveness of specified drugs in lowering hypertension.

Methods: The study conducted was retrospective, prospective, comparative study extended over 1 year on 28 patients based on inclusion and exclusion criteria.

Results: Both these drugs cause regression of LVH with a decrease in LV mass index value; it is seen that amlodipine is better in controlling elevated blood pressure (BP), especially diastolic BP. In statistical analysis, regression of LVH was found to be correlated with reduction of BP.

Conclusion: Incidence of adverse effect was found to be prominent in amlodipine group. Thus, losartan was found to be better in regressing LVH than amlodipine.

Keywords: Left ventricular hypertrophy, Amlodipine, Losartan.

(C) 2017 The Authors. Published by Innovare Academic Sciences Pvt Ltd. This is an open access article under the CC BY license (http://creativecommons. org/licenses/by/4. 0/) DOI: http://dx.doi.org/10.22159/ajpcr.2017.v10i5.16928

\section{INTRODUCTION}

The ventricles are the chamber in the heart responsible for pumping of blood off the heart. The ventricle due to constant exposure to increased pressure is susceptible to hypertrophy called ventricular hypertrophy, which means the thickening of walls of ventricle in the heart. In general, cardiac hypertrophy is divided broadly as physiological hypertrophy [1], which results as a normal response to healthy exercise or pregnancy and pathological hypertrophy [2,3], which is the response to stress or disease such as hypertension, myocardial infarction, or neurohormonal profile. According to the physiology of hypertrophy, it is categorized as eccentric and concentric hypertrophy. Left ventricular hypertrophy (LVH) is defined as increase in mass of $\mathrm{LV}$ which predominantly results from a chronic increase in after load of the LVH caused by the hypertension mainly associated with increased peripheral resistance, although there is a genetic component called osteoglycan, proved to be involved in the development of particular pathological condition [4,5]. In hypertrophied myocardium, there is a reduction in density of capillaries [6], and thus, it may be more susceptible to effects of ischemia $[7,8]$. In the mechanism of LVH, the etiology states that it develops by a group of physiological activation which includes increased LV requirement, increased resistance to LV evacuation, and inefficient emptying of LV [9]. Pathway involved in response to physiological activation includes three mechanisms which are increasing cross bridge formation by Frank-Starling methods, increase in muscle mass, and neurohumoral activation.

Targeting the mechanism responsible for LVH could slow down the process. Factors promoting LVH are hypertension, neurohumoral factors, genetic influence, obesity, aortic stenosis. Symptoms appear as the LVH progresses and it includes dyspnea, orthopnea, chest pain, palpitations, dizziness, or fainting. LVH is diagnosed by method such as echocardiography, cardiac magnetic resonance imaging evaluation, and electrocardiography [10]. Earlier experiment showed that the sympathetic nervous system-induced LVH in number of situations increases LVH mass.

Most of the known action of angiotensin-II is mediated through AT receptor subtype [11]. The stimulation of $\mathrm{AT}_{2}$ receptors may aggravate antihypertensive effect by natriuresis, but the role of $\mathrm{AT}_{2}$ receptor subtype in LVH patients is unknown [12]. The study of renal effect of losartan by Dahlof et al. put a hint on its consistent uricosuric effect. Data from the losartan intervention for endpoint reduction in hypertension study showed a significant reduction in the risk of stroke in hypertensive patients with LVH [13]. Evaluation of losartan in the elderly study substantiated that angiotensin-II antagonist losartan is as effective angiotensin converting enzyme (ACE) inhibitors in safe guarding patients from morbidity and mortality due to cardiovascular disease.

In the grounds of plethora of antihypertensive drug used in the treatment of LVH, the study aims to access the chemical effectiveness, adverse events profile, and blood pressure (BP) regulating effect of the drugs, losartan and amlodipine. Losartan and amlodipine are the drugs with better patient outcome and therapeutic profile with additional benefits of lesser adverse drug reaction (ADR) events and increased half-life in regulating hypertension in their concerned classes. Thus, meeting proposed objectives of the study serves to be a prominent module for treatment of $\mathrm{LVH}$.

\section{MATERIALS AND METHODS}

- Design of the study was retrospective prospective, comparative study.

- Duration of the study and data collection were done for 8 months from October 2012 to June 2013. 
The study population included all patients diagnosed to have LVH with hypertension, confirmed by echocardiography, taking either losartan $50 \mathrm{mg}$ /day or amlodipine $5 \mathrm{mg}$ /day in monotherapy under the Cardiology Department and those who satisfied the inclusion and exclusion criteria were selected for the study.

Out of 62 patients diagnosed to have LVH, 33 were found to be taking losartan $50 \mathrm{mg}$ /day or amlodipine $5 \mathrm{mg} /$ day as monotherapy, of which five patients are were not on regular follow-up; thus, the sample size was confirmed to be 28 patients.

\section{Methodology}

The study was carried out after getting approval from the Research and Ethics Committee. The demographic details of the patients, laboratory data, drug therapy details including dose, frequency, duration of therapy, etc., were collected from the medical records as well as direct interview of the patients or his/her caregivers using a predesigned data collection form. For the baseline data, parameters such as interventricular septum thickness, posterior wall thickness (PWT), and $\mathrm{LV}$ internal diameter at the diastole were recorded by means of echocardiographic evaluation; baseline BP values also were collected earlier and were asked to monitor BP values once in a fortnight; calculation of LV mass was carried out by Devereux formula.

Indexed LV mass is calculated by dividing LV mass by body surface area $\left(\mathrm{m}^{2}\right)$ which is termed as left ventricular mass index (LVMI).

During the follow-up therapy period of 6-8 months, LV mass and LVMI were again calculated to measure whether LVH regressed in the study patients. Adverse events occurred in the study patients were monitored by means of Naranjo scale.

\section{RESULTS}

The demographic details of 28 patients included in the study were monitored to assess the effect of losartan and amlodipine in LVH regression, $\mathrm{BP}$ regulation, and related ADRs of specific drugs based on patient details which include as follows:

- Age of patient

- Gender of the patients

- Comorbidities of patients

- Social history

- Number of patients on severity of LVH

- Management of LVH.

\section{Age distribution of the patients}

Maximum age group of patient in study was found to be 62 years and minimum as 32 years. The mean age of the patients was given to be as $50 \pm 11$ years.

\section{Gender distribution of the patient}

Out of the 28 patients, the male-female ratio was found to be 3:1, i.e., the male patients predominate over the female patients.

\section{Comorbidities of the patients}

Dyslipidemia was the most populous comorbidity among the study population constituting $50 \%$ followed by diabetes mellitus $22 \%$.

\section{Social history (Table 1)}

\section{Table 1: Social history}

\begin{tabular}{ll}
\hline Social history & Number of patients \\
\hline Smoking & 2 \\
Alcohol & 3 \\
Alcohol+smoking & 1 \\
Oil excess & 2 \\
Ex-alcoholic & 3 \\
\hline
\end{tabular}

Number of patients on the severity of LVH

Patients were categorized by modified Simpson's rule and the data obtained were as follows.

\section{Management of LVH (Table 2)}

LVH was treated with losartan $50 \mathrm{mg} /$ day or amlodipine $5 \mathrm{mg} /$ day, and the therapy was continued for 6-8 months which was categorized as two groups.

\section{Effect of LVH regression}

Both amlodipine and losartan used in the treatment were found to be effective in regressing LVH in different magnitude (Tables 3-5)

\section{Effect on BP regulation}

In accordance with $\mathrm{LVH}$ regression, the drugs also were effective in regulating hypertension thus attaining a clinical goal. After 6-8 months of treatment, BP values were altered in both groups (Tables 6-8).

Table 2: Management of LVH

\begin{tabular}{ll}
\hline Treatment & Number of patients (\%) \\
\hline Amlodipine & $14(50)$ \\
Losartan & $14(50)$ \\
Total & $28(100)$ \\
\hline
\end{tabular}

LVH: Left ventricular hypertrophy

Table 3: Effect of losartan

\begin{tabular}{llll}
\hline Parameter & $\begin{array}{l}\text { Before } \\
\text { treatment }\end{array}$ & $\begin{array}{l}\text { After } \\
\text { treatment }\end{array}$ & p value \\
\hline IVS $(\mathrm{cm})$ & $1.36 \pm 0.1$ & $1.30 \pm 0.11$ & 0.0001 \\
PWT $(\mathrm{cm})$ & $1.2271 \pm 0.1134$ & $1.20 \pm 0.1814$ & 0.001 \\
LVIDd $(\mathrm{cm})$ & $4.66 \pm 0.51$ & $4.31 \pm 0.59$ & 0.0 \\
LV mass $(\mathrm{g})$ & $234.71 \pm 45.65$ & $209.21 \pm 43.09$ & 0.0 \\
LVMI $\left(\mathrm{g} / \mathrm{m}^{2}\right)$ & $135.5 \pm 26.98$ & $121.36 \pm 25.83$ & 0.0 \\
\hline
\end{tabular}

IVS: Interventricular septum, PWT: Posterior wall thickness, LVIDd: Left ventricular diastolic internal diameter, LV: Left ventricular, LVMI: Left ventricular mass index

Table 4: Effect of amlodipine

\begin{tabular}{llll}
\hline Parameter & $\begin{array}{l}\text { Before } \\
\text { treatment }\end{array}$ & $\begin{array}{l}\text { After } \\
\text { treatment }\end{array}$ & p value \\
\hline IVS $(\mathrm{cm})$ & $1.37 \pm 0.09$ & $1.29 \pm 0.08$ & 0.001 \\
PWT $(\mathrm{cm})$ & $1.27 \pm 0.1173$ & $1.217 \pm 0.1195$ & 0.002 \\
LVIDd $(\mathrm{cm})$ & $4.76 \pm 0.36$ & $4.59 \pm 0.35$ & 0.001 \\
LV mass $(\mathrm{g})$ & $251 \pm 51.29$ & $230 \pm 47.68$ & 0.0 \\
LVMI $\left(\mathrm{g} / \mathrm{m}^{2}\right)$ & $139.07 \pm 26.9$ & $126.29 \pm 25.086$ & 0.0001 \\
\hline
\end{tabular}

IVS: Interventricular septum, PWT: Posterior wall thickness, LVIDd: Left ventricular diastolic internal diameter, LV: Left ventricular, LVMI: Left ventricular mass index

Table 5: Effect of losartan versus amlodipine on LVH regression

\begin{tabular}{llll}
\hline Parameter & \multicolumn{2}{l}{$\begin{array}{l}\text { Difference in } \\
\text { value (before-after) }\end{array}$} & p value \\
\cline { 2 - 3 } & Losartan & Amlodipine & \\
\hline IVS $(\mathrm{cm})$ & $0.0564 \pm 0.041$ & $0.0735 \pm 0.063$ & 0.002 \\
PWT $(\mathrm{cm})$ & $0.02 \pm 0.03$ & $0.053 \pm 0.039$ & 0.001 \\
LVIDd $(\mathrm{cm})$ & $0.2242 \pm 0.206$ & $0.165 \pm 0.15$ & 0.0 \\
LV mass $(\mathrm{g})$ & $25.5 \pm 10.53$ & $20 \pm 13.02$ & 0.0 \\
LVMI $\left(\mathrm{g} / \mathrm{m}^{2}\right)$ & $14.143 \pm 6.1$ & $12.286 \pm 3.09$ & 0.0001 \\
\hline
\end{tabular}

IVS: Interventricular septum, PWT: Posterior wall thickness, LVIDd: Left ventricular diastolic internal diameter, LV: Left ventricular, LVMI: Left ventricular mass index, LVH: Left ventricular hypertrophy 
Table: 6: Effect of losartan on BP regulation

\begin{tabular}{llll}
\hline Parameter & Before therapy & After therapy & p value \\
\hline SBP & $147.36 \pm 9.44$ & $137.43 \pm 10.06$ & 0.0 \\
DBP & $87.14 \pm 3.98$ & $85.43 \pm 4.67$ & 0.001 \\
\hline
\end{tabular}

BP: Blood pressure, SBP: Systolic blood pressure, DBP: Diastolic blood pressure

Table: 7: Effect of amlodipine on BP regulation

\begin{tabular}{llll}
\hline Parameter & Before therapy & After therapy & p value \\
\hline SBP & $148.5 \pm 14.66$ & $139.7 \pm 15.13$ & 0.0 \\
DBP & $89.57 \pm 7.24$ & $84.36 \pm 6.22$ & 0.017 \\
\hline
\end{tabular}

BP: Blood pressure, SBP: Systolic blood pressure, DBP: Diastolic blood pressure

Table 8: Losartan versus amlodipine in BP

\begin{tabular}{llll}
\hline Parameter & \multicolumn{2}{l}{$\begin{array}{l}\text { Difference in value of } \\
\text { BP (before-after) }\end{array}$} & p value \\
\cline { 2 - 3 } & Losartan & Amlodipine & \\
\hline SBP $(\mathrm{mmHg})$ & $9.929 \pm 5.79$ & $8.786 \pm 8.322$ & 0.04 \\
DBP (mmHg) & $1.7143 \pm 2.812$ & $5.214 \pm 5.899$ & 0.002 \\
\hline BP. Blonn
\end{tabular}

Correlation of BP value with LVMI (Tables 9 and 10)

Table 9: Correlation of SBP values with LVMI

\begin{tabular}{llll}
\hline Drug & LVMI $\left(\mathrm{g} / \mathbf{m}^{2}\right)$ & SBP $(\mathbf{m m H g})$ & Correlation \\
\hline Losartan & $121.36 \pm 25.83$ & $137.43 \pm 10.06$ & 0.17 \\
Amlodipine & $126.29 \pm 25.086$ & $139.7 \pm 15.13$ & 0.2 \\
\hline
\end{tabular}

LVMI: Left ventricular mass index, SBP: Systolic blood pressure

Table 10: Correlation of DBP values with LVMI

\begin{tabular}{llll}
\hline Drug & LVMI $\left(\mathbf{g} / \mathbf{m}^{2}\right)$ & DBP $(\mathbf{m m H g})$ & Correlation \\
\hline Losartan & $121.36 \pm 25.83$ & $85.43 \pm 4.67$ & 0.21 \\
Amlodipine & $126.29 \pm 25.086$ & $84.36 \pm 6.22$ & 0.41 \\
\hline
\end{tabular}

LVMI: Left ventricular mass index, DBP: Diastolic blood pressure

\section{Adverse events}

Twenty-eight patients had been monitored for any adverse events, specifically due to drugs losartan or amlodipine in the course of the study. Among the whole study sample, 2, i.e., $14 \%$ of patients taking amlodipine complained of peripheral edema, whereas in the losartan group, no one complained of any adverse events.

\section{DISCUSSION}

Hypertensive LV is a risk factor for coronary artery disease, heart failure, arrhythmias, and sudden death [14]. Therefore, regression of LVH is an important pharmacological objective. The goal of the present study was to compare the effect of angiotensin-II type 1 receptor blockers losartan against calcium channel blockers amlodipine in controlling LVH.

Generally, LVH is more predominant in males than in females (Figs. 1 and 2), which was comparable with demographic of Thürmann et al.'s [15] study. Most number of the patients was in the age group 50-59 years and least number of patients was under the age group of 30-39 years (Fig. 3). Dyslipidemia was the most populous comorbidity among the study population constituting $50 \%$ followed by diabetes mellitus $22 \%$ (Fig. 4). The prevalence of LVH has recently been estimated with a sitting diastolic BP (DBP) up to $115 \mathrm{mmHg}$ [16].

The degree of regression of LVH by antihypertensive drugs seems different and independent from their magnitude of antihypertensive effect [17]. The steering factors for the development of cardiac hypertrophy, other than chronic shoot up in pressure or volume overload, are elevation in plasma levels of ACE, plasma aldosterone levels, angiotensin concentration. The risk of cardiovascular morbidity and mortality increases in geometric progression if both LVH and hypertension persist in patients. The duration of the study was 6 months which is similar to the study conducted by Nalbantgil et al. [18]. In a comparative trial between losartan and atenolol conducted by Dahlof

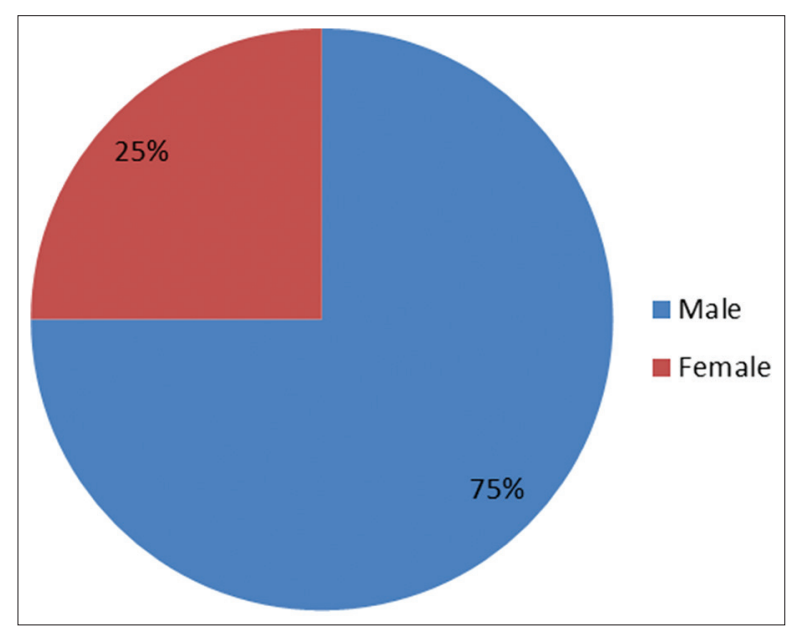

Fig. 1: Gender distribution of the patient

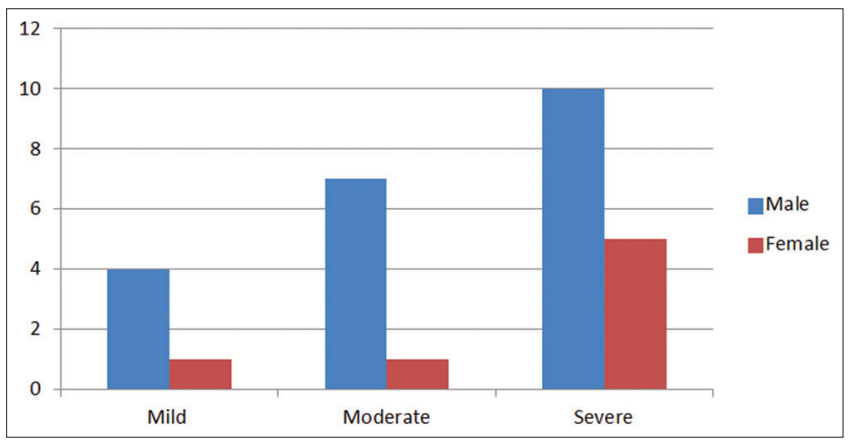

Fig. 2: Number patients on the severity of left ventricular hypertrophy. X-axis represents the severity of left ventricular hypertrophy while the Y-axis represents the number of patients

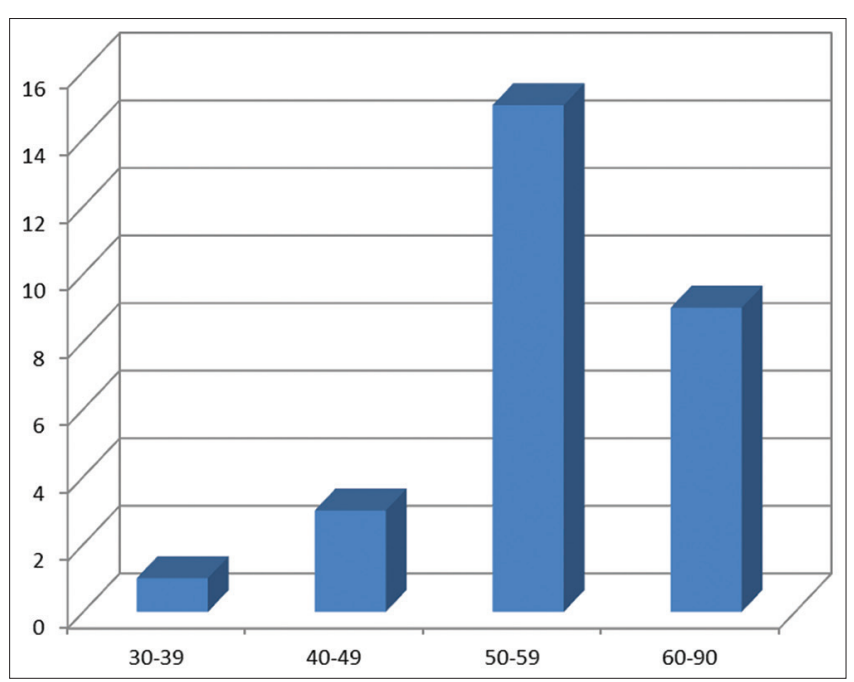

Fig. 3: Age distribution. $X$-axis indicates the age group while the Y-axis indicates the number of patients 


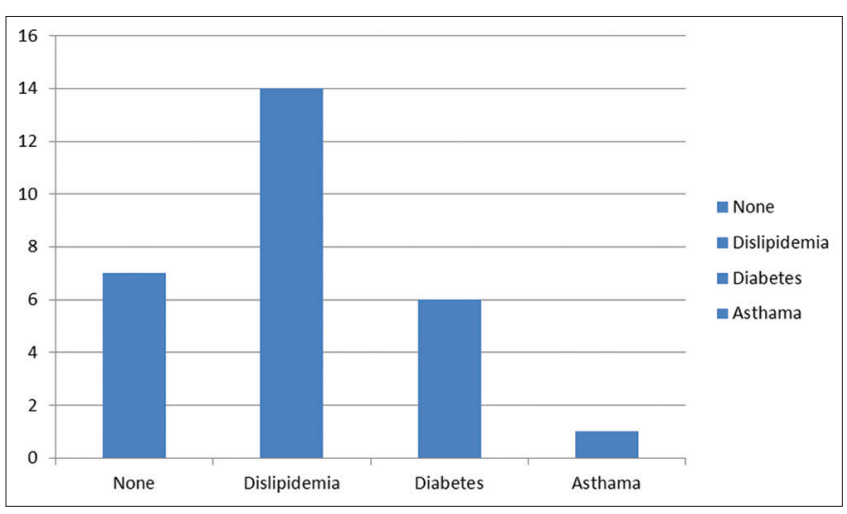

Fig. 4: Comorbidities of the patients

et al. after 36 weeks of treatment with losartan, regression in LVMI was similar to this study [19]. There was observed a significant reduction in values of interventricular septum, PWT, LV diastolic internal diameter, and LVMI in both losartan group and amlodipine group. Indexed LV mass reduced in both groups by 6 months; effects of reducing LVMI in losartan study group was found to be more effective than amlodipine study group, which was more comparable with the results of Fogari et al.'s study [20] (Table 5).

As per Levy et al.'s study [21], there was a significant decrease in both the study group, wherein systolic BP (SBP) reduced more in losartan group and DBP reduction was seen more in amlodipine group (Table 8). Effect of renin-angiotensin-aldosterone system blockade by angiotensin receptor antagonist or ACE inhibitors was seemed to have a prominent effect in regressing LVH. Correlation between SBP and LVMI was found to be 0.17 and 0.2 in losartan and amlodipine, respectively (Table 9); correlation between DBP and LVMI was found to be 0.21 in losartan patients and 0.41 in amlodipine patients (Table 10). The ADR events of both groups were monitored and it was observed that only patients in amlodipine group experienced ADR such as peripheral edema [22], which was comparable with ADR occurred in Rosendorff et al.'s [23] study.

\section{CONCLUSION}

The study was focused to assess the clinical effectiveness of losartan and amlodipine in regressing LVH in patients with hypertension. A total of 28 patients completed the study, of which 14 were on losartan and 14 were on amlodipine. Both of these cause regression in LVH with decreases in the LVMI value. In losartan group, LVMI was reduced by magnitude of $14 \mathrm{~g} / \mathrm{m}^{2}$, and in amlodipine group, it was reduced by magnitude of $12 \mathrm{~g} / \mathrm{m}^{2}$. Thus, losartan is considered to be the best in regressing LVH compared with amlodipine in a period of 6-8 months. The drugs were also monitored for the effect in regulating hypertension. Both losartan and amlodipine reduced mean BP value. Of both the drugs, it was assessed that amlodipine is better in controlling elevated BP especially DBP. Both the drugs reactions brought regression of LVH in 6 months. For a better clinical outcome, the drug has to be continued for a comparatively longer period. While monitoring ADR, 2 patients who were on amlodipine complained on adverse effects such as peripheral edema, whereas no adverse effect was reported in losartan group. This never implies that losartan is free of adverse events because the study population of this particular study was small.

\section{REFERENCES}

1. Mone SM, Sanders SP, Colan SD. Control mechanisms for physiological hypertrophy of pregnancy. Circulation 1996;94(4):667-72.
2. Acharya PV. Irreparable DNA damage by industrial pollutants in pre mature ageing chemical carcinogenesis and cardiac hypertrophy experiments and theory. Isr J Med Sci 1987;13:440-2.

3. Mann DL, Bristow MR. Mechanisms and models in heart failure: The biomechanical model and beyond. Circulation 2005;111(21):2837-49.

4. Kannel WB. Left ventricular hypertrophy as a risk factor in arterial hypertension. Eur Heart J 1992;13 Suppl D:82-8.

5. Laufer E, Jennings GL, Korner PI, Dewar E. Prevalence of cardiac structural and functional abnormalities in untreated primary hypertension. Hypertension 1989;13(22):151-62.

6. Beache GM, Herzka DA, Boxerman JL, Post WS, Gupta SN, Faranesh AZ, et al. Attenuated myocardial vasodilator response in patients with hypertensive hypertrophy revealed by oxygenation-dependent magnetic resonance imaging. Circulation 2001;104(11):1213-5

7. Carluccio E, Tommasi S, Bentivoglio M, Buccolieri M, Filippucci L, Prosciutti L, et al. Prognostic value of left ventricular hypertrophy and geometry in patients with a first, uncomplicated myocardial infarction. Int J Cardiol 2000;74:176-83.

8. Burke AP, Farb A, Liang YH, Smialek J, Virmani R. Effect of hypertension and cardiac hypertrophy on coronary artery morphology in sudden cardiac death. Circulation 1996;94(12):3138-45.

9. Phillips RA. Etiology, pathophysiology, and treatment of left ventricular hypertrophy: Focus on severe hypertension. J Cardiovasc Pharmacol 1993;21 Suppl 2:S55-62.

10. Zou Y, Song L, Wang Z, Ma A, Liu T, Gu H, et al. Prevalence of idiopathic hypertrophic cardiomyopathy in China: A populationbased echocardiographic analysis of 8080 adults. Am J Med 2004;116(1):14-8

11. Goodfriend TL, Elliott ME, Catt KJ. Angiotensin receptors and their antagonists. N Engl J Med 1996;334:1649-54.

12. Brink M, Erne P, de Gasparo M, Rogg H, Schmid A, Stulz P, et al. Localization of the angiotensin II receptor subtypes in the human atrium. J Mol Cell Cardiol 1996;28(8):1789-99.

13. Dahlof B, Devereux R, deFaire U, Fyhrquist F, Hedner T, Ibsen H, et al. Baseline characteristics of the LIFE (Losartan intervention for endpoint reduction) in hypertension study. Hypertension 1997;15(4):34-7

14. Pelliccia A, Maron MS, Maron BJ. Assessment of left ventricular hypertrophy in a trained athlete: Differential diagnosis of physiologic athlete's heart from pathologic hypertrophy. Prog Cardiovasc Dis 2012;54(5):387-96.

15. Thürmann PA, Kenedi P, Schmidt A, Harder S, Rietbrock N. Influence of the angiotensin II antagonist valsartan on left ventricular hypertrophy in patients with essential hypertension. Circulation 1998;98(19):2037-42.

16. Zabalgoitia M. Left ventricular mass and function in primary hypertension. Am J Hypertens 1996;9(8):55s-9.

17. Dahlöf B, Pennert K, Hansson L. Reversal of left ventricular hypertrophy in hypertensive patients. A metaanalysis of 109 treatment studies. Am J Hypertens 1992;5(2):95-110.

18. Nalbantgil S, Yilmaz H, Gurun C, Özerkan F, Nalbantgil I, Önder R, et al. Effect of valsartan and enalapril on regression of left ventricular hypertrophy in patients with mild to moderate hypertension. Curr Ther Res 2000;61(6);331-8.

19. Dahlof B, Zanchetti A, Diez J, Nicholls MG, Yu CM, Barrios V, et al. Effects of losartan and atenolol on left ventricular mass and neurohormonal profile in patients with essential hypertension and left ventricular hypertrophy. J Hypertens 2002;20(9):1855-64.

20. Fogari R, Mugellini A, Destro M, Corradi L, Lazzari P, Zoppi A, et al. Losartan and amlodipine on myocardial structure and function: A prospective, randomized, clinical trial. Diabet Med 2012;29(1):24-31.

21. Levy D, Garrison RJ, Savage DD, Kannel WB, Castelli WP. Prognostic implications of echocardiographically determined left ventricular mass in the Framingham heart study. N Engl J Med 1990;322(22):1561-6.

22. Shetty K, Shetty R, Rao P, Vivek G, Naveenchandran GS, Razak A, et al. Evaluation of causative factors in amlodipine induced pedal edema. Indian J Pharm Pharm Sci 2016;8(11):303-6.

23. Rosendorff C, Dubiel R, Xu J, Chavanu KJ. Comparison of olmesartan medoxomil versus amlodipine besylate on regression of ventricular and vascular hypertrophy. Am J Cardiol 2009;104(3):359-65. 